Revista da Rede Brasileira de História da Geografia e Geografia Histórica

$11 \mid 2019$

Mapas e mapeamentos: conhecer, apresentar e agir

\title{
Apontamentos biobibliográficos sobre Silvia Fernanda de Mendonça Figueirôa
}

Rafael Augusto Andrade Gomes

(2) OpenEdition

Journals

Edição electrónica

URL: https://journals.openedition.org/terrabrasilis/4158

DOI: 10.4000/terrabrasilis.4158

ISSN: 2316-7793

Editora

Rede Brasileira de História da Geografia e Geografia Histórica

Refêrencia eletrónica

Rafael Augusto Andrade Gomes, «Apontamentos biobibliográficos sobre Silvia Fernanda de Mendonça Figueirôa», Terra Brasilis [Online], 11 | 2019, posto online no dia 31 agosto 2019, consultado o 05 dezembro 2022. URL: http://journals.openedition.org/terrabrasilis/4158 ; DOI: https://doi.org/ 10.4000/terrabrasilis. 4158

Este documento foi criado de forma automática no dia 5 dezembro 2022.

All rights reserved 


\title{
Apontamentos biobibliográficos sobre Silvia Fernanda de Mendonça Figueirôa
}

\author{
Rafael Augusto Andrade Gomes
}

\section{NOTA DO EDITOR}

O presente texto serve como apresentação ao artigo de Silvia Figueirôa "Algumas questões metodológicas relativas à história de instituições científicas", publicado originalmente em 1991 no livro Ciencia y Tecnología: estudios del pasado y del futuro (San José, Costa Rica, Asociación Costarricense de Historia y Filosofía de la Ciencia, pp. 253-270) e republicado neste mesmo número da Terra Brasilis.

1 Comecemos com o desafio proposto: escrever algumas linhas de apresentação biobibliográfica de Silvia Figueirôa. Confesso que a simples ideia de preambular um texto dessa autora é desafiadora. Para quem escreve sobre a vida e obra de alguém, é grande, e por vezes incontrolável, o ímpeto de demonstrar a existência individual como uma epopeia. A partir disso, é praticamente impossível livrar-se de um esquema narrativo teleológico e totalizante. Em contraste com a biografia-epopeia, há pelo menos outra forma possível de contar uma vida: os fragmentos de memória, pormenores isolados que, em conjunto, compõem uma narrativa biográfica descontínua.

2 Apesar da vivacidade dos fragmentos de memória e de sua capacidade de colorir as narrativas biográficas, um relato do desenvolvimento factual da vida não é completamente descartável e prescindível aos iniciantes ou, ainda, ao leitor casual da Terra Brasilis. É por isso que, em resposta ao desafio de apresentar com brevidade a vida e obra de Silvia Figueirôa, só me foi possível elaborar um texto informativo. Tão limitado e fragmentário quanto qualquer outra narrativa biográfica, este texto seguirá 
uma estrutura diacrônica de uma dimensão específica da vida acadêmica de Silvia Figueirôa: trajetória formativa e profissional no Ensino Superior.

3 Professora e pesquisadora da Universidade Estadual de Campinas, Silvia Figueirôa, que iniciou o curso de graduação em Geologia na Universidade de São Paulo (USP) no ano de 1977, acumula textos e livros fecundos sobre história das geociências no Brasil e na América Latina. Um ano depois de concluir a graduação, em 1983, e sob a supervisão de Maria Amélia Mascarenhas Dantes, ingressou no curso de mestrado do Programa de Pós-Graduação em História Social (PPGHS) da USP - criado em 1971, o PPGHS é um dos mais antigos e prestigiados programas de pós-graduação em História Social do Brasil.

Embora defendida no ano de 1987, a dissertação, intitulada "Modernos bandeirantes: a Comissão Geográfica e Geológica de São Paulo e a exploração científica do território paulista (1886-1931)" (Figueirôa, 1987a), e uma publicação coordenada por Silvia Figueirôa no âmbito do Instituto Geológico de São Paulo (Figueirôa, 1985) antecipam os exemplos e algumas das teses apresentadas no texto ora republicado pela Terra Brasilis (Figueirôa, 1991). Rastrear os antecedentes do texto de Figueirôa (1991) leva-nos inevitavelmente a considerar a trajetória formativa da autora na aurora dos anos 1980 (ver o editorial do presente número da Terra Brasilis).

5 No PPGHS da USP, Silvia Figueirôa, ainda supervisionada por Maria Amélia Mascarenhas Dantes, inicia sua pesquisa de doutoramento no ano de 1988. Para seguir o caminho pavimentado pelas investigações precedentes, a autora se dedica ao estudo da história institucional das ciências geológicas. Defendida em 1992, a tese de doutoramento de Silvia Figueirôa, intitulada "Ciência na busca do 'Eldorado': a institucionalização das ciências geológicas no Brasil (1808-1907)", dá o compasso de suas pesquisas posteriores sobre a história social e institucional das ciências geológicas no Brasil, sobretudo de sua obra seminal (Figueirôa, 1997).

De 1987 a 2013, Silvia Figueirôa foi professora do Instituto de Geociências da Universidade Estadual de Campinas (UNICAMP); em 2014, transferiu-se para a Faculdade de Educação da mesma instituição de ensino e lá permanece até hoje. Apesar de ter se tornado integrante do quadro docente da Faculdade de Educação da UNICAMP apenas em 2014, Silvia Figueirôa, pelo menos desde o ano de 2001, quando obteve a livre-docência na UNICAMP, faz pesquisas e orienta alunos de pós-graduação com relação ao ensino de geociências. Ainda durante a primeira década do século XXI, nos anos de 2002 e 2006, respectivamente, Silvia Figuerôa tornou-se professora titular da UNICAMP e realizou um pós-doutorado na École des Hautes Études en Sciences Sociales (França).

7 Depois de aproximadamente quatro décadas de pesquisa e ensino com excelência, o reconhecimento da relevância de Silvia Figueirôa ao campo da História das Ciências advém de sua participação séria e ativa em diversos espaços institucionais: 1) parecerista em mais de 25 periódicos sobre História, Ciências e História das Ciências no Brasil e na Europa; 2) fez ou faz parte do Conselho Editorial de ao menos 15 periódicos brasileiros ou estrangeiros. Já contribuiu com um artigo para a Terra Brasilis (Figueirôa, 2000) e, atualmente, também faz parte do Conselho Consultivo da revista; 3 ) membra da International Commision on the History of Geological Sciences, da History of Earth Sciences, da Sociedade Latino-americana de História da Ciência e da Tecnologia (SLHCT) e de outras diversas associações acadêmico-profissionais de historiadores da ciência.

Publicado no final dos anos 1990, o livro "As ciências geológicas no Brasil: uma história social e institucional (1875-1934)" (Figueirôa, 1997) permanece como um dos mais 
conhecidos sobre a História das Ciências no Brasil. Tornou-se, para os anos 1990 e 2000, um ponto de passagem obrigatório para a compreensão do estado das pesquisas em História das Ciências de uma geração de pesquisadores, assim como outros livros precedentes também o são para outros momentos, temas e lugares (Azevedo, 1956; Carvalho, 1978; Schwartmann, 1979; Ferri \& Motoyama, 1979-1981).

9 Ao dar continuidade e inovar nos estudos institucionais que marcaram a trajetória de Maria Amélia Mascarenhas Dantes $(1980,1988)$, sua orientadora na pós-graduação, Silvia Figueirôa estudou sistematicamente a institucionalização das ciências geológicas. Por outro lado, a exemplo de sua participação na Sociedade Latino-americana de História da Ciência e da Tecnologia (e no periódico Quipu, publicação da SLHCT criada em 1984), foi uma pesquisadora que se empenhou em ampliar os espaços institucionais para uma História das Ciências escrita a partir da América Latina (Figueirôa, 1987b, 1997, 2000). A dimensão institucional conecta, assim, partes da trajetória acadêmicoprofissional com o próprio conteúdo da obra de Silvia Figueirôa.

10 Além dos estudos sobre institucionalização das geociências no Brasil, Silvia Figueirôa tem se dedicado à investigação de uma ampla gama de temas: documentação científica; os livros-texto de geologia e o ensino de geociências; produção, divulgação e comunicação científica de instituições formais e não formais de ensino; origem e história das técnicas de exploração petrolífera. Sobre o último tema, inclusive, a autora coordenou a organização de um livro no início deste ano (Figueirôa et al., 2019).

11 Com a apresentação factual da trajetória de Silvia Figueirôa, não procuramos construir nem uma imagem laudatória, nem, em oposição à sua glorificação, um mosaico de fragmentos de memória que não fizessem jus à relevância da autora para a história $\mathrm{e}$ historiografia das ciências geológicas e das geociências no Brasil. Antes de decidir se esta narrativa sobre a biografia de Silvia Figueirôa é razoável, convidamos o leitor iniciado a remodelá-la com suas próprias reminiscências sobre a trajetória e obra da autora. Aos leitores iniciantes e casuais, esperamos ter oferecido uma história narrável de uma trajetória que, ainda neste instante, continua sendo (re)escrita por Silvia Figueirôa e por outros que se propõem a contá-la.

\section{BIBLIOGRAFIA}

Azevedo, Fernando de (org.) (1956). As ciências no Brasil. 2 volumes. São Paulo: Melhoramentos. Carvalho, José Murilo de (1978). A Escola de Minas de Ouro Preto. O peso da glória. São Paulo: Companhia Editora Nacional.

Dantes, Maria Amélia Mascarenhas (1980). "Institutos de pesquisa científica”. In: Ferri, Mário; Motoyama, Shozo (orgs.) (1980). História das ciências no Brasil, v. 2. São Paulo: EPU/EDUSP, pp. 341-380.

Dantes, Maria Amélia Mascarenhas (1988). "Fases da implantação da ciência no Brasil". Cuadernos Quipu, Revista da Sociedade Latino-americana de História da Ciência e da Tecnologia, v. 5, n. 5, pp. 265-275. 
Ferri, Mário; Motoyama, Shozo (orgs.) (1979-1981). História das ciências no Brasil. 3 volumes. São Paulo: EPU/EDUSP.

Figueirôa, Silvia (1985). Um século de pesquisas em Geociências. 1. ed. São Paulo: Instituto Geológico de São Paulo.

Figueirôa, Silvia (1987a). Modernos bandeirantes: a Comissão Geográfica e Geológica de São Paulo e a exploração científica do território paulista (1886-1931). Dissertação de Mestrado (História Social). Programa de Pós-Graduação em História Social da Universidade de São Paulo.

Figueirôa, Silvia (1987b). Um exemplo de aplicação da Semiótica à história da ciência através da análise de fotografias de expedições geocientíficas. Cuadernos Quipu, México, v. 4, n. 3, pp. 433-445.

Figueirôa, Silvia (1991). “Algumas questões metodológicas relativas à história de instituições científicas”. In: Zuniga, Angel Ruiz (org.). Ciencia y tecnología: estudios del passado y del futuro. 1. ed. San José: Guayacán, 1991, pp. 143-154.

Figueirôa, Silvia (1992). Ciência na busca do 'Eldorado': a institucionalização das ciências geológicas no Brasil (1808-1907). Tese de Doutorado (História Social). Programa de Pós-Graduação em História Social da Universidade de São Paulo.

Figueirôa, Silvia (1997). As ciências geológicas no Brasil: uma história social e institucional. 1875-1934. 1. ed. São Paulo: Editora Hucitec.

Figueirôa, Silvia (org.) (2000). Um olhar para o passado. História das ciências na América Latina. 1. ed. São Paulo: Editora da UNICAMP.

Figueirôa, Silvia; Good, Gregoy; Peyerl, Drielli (eds.) (2019). History, Exploration \& Exploitation of Oil and Gas. 1. ed. Genebra: Springer.

Schwartmann, Simon (1979). Um espaço para a ciência: a formação da comunidade científica no Brasil. São Paulo: Companhia Editora Nacional.

\section{AUTOR}

RAFAEL AUGUSTO ANDRADE GOMES

Editor Adjunto da Terra Brasilis 